\title{
-Research Note - \\ Effect of TDN Levels of Concentrate Diet on Plasma Glucose Levels in Calves
}

\author{
Hiroshi Sato, Takeru Kobayashi, Hiroaki Shishido \\ and Tatsuo TomaBECH * \\ National Institute of Animal Industry, Chiba-shi 280 \\ *Gunma Animal Industry Experiment Station, Fujimi, Gunma 371-01
}

(Received February 20, 1976)

In the ruminant, blood glucose levels in young animals are higher than those of mature animals and these levels fall to adult value usually within 3 months of age ${ }^{11}$. It has been known that the blood glucose levels were affected by the methods of weaning ${ }^{2)}$ and by the diets given ${ }^{3,4)}$. But the glucose levels in whole blood are considerably different from those in plasma ${ }^{5)}$, and the relationship between the TDN content of the diets and whole blood or plasma glucose levels has not been clarified enough in young calves.

In the present experiment, two concentrate diets containing $75 \%$ and $65 \%$ TDN were given to calves to determine the effect of different TDN levels of the diet on plasma glucose levels.

\section{Materials and Methods}

Twelve 6-10 days old male Holstein calves were used and they were kept in individual pens until 12 weeks of age. Whole milk was given at the rate of $20 \%$ of metabolic body size (B. W. ${ }^{0.75}$ ) every morning throughout the experimental period, but the maximum amount of daily milk given was limited to $6 \mathrm{~kg}$. The milk requirements were estimated once a week. Six calves were fed the concentrate diet containing 75\% TDN (diet A) and the other six calves were fed the concentrate diet of $65 \%$ TDN (diet B). These diets were prepared as creep feed for beef calves. DCP level was about $15 \%$ in both diets. Italian ryegrass hay (TDN 56\%) was fed to all the calves. The animals were allowed access ad libitum to these feeds and water.

Once a week, blood samples were taken from jugular vein into the heparinized tube immediately before suckling. It has been suggested that plasma glucose levels were more susceptible to nutritional status in the body than whole blood glucose levels in young calves ${ }^{2}$. Consequently, plasma was prepared for glucose level determination. Blood plasma was separated by centrifugation within 30 minutes after sampling. Plasma glucose levels were measured by glucoseoxidase method (Glucostat; Worthington Biochem. Corp., USA) within 3 hours after the sampling.

\section{Results and Discussion}

Mean feed intake throughout the experimental period was $57 \mathrm{~kg}$ of concentrate diet and $40 \mathrm{~kg}$ of hay in the calves fed diet A, and $51 \mathrm{~kg}$ of concentrate diet and $43 \mathrm{~kg}$ of hay in the calves fed diet $B$, respectively. The average daily gain during the experimental period was $0.83 \mathrm{~kg}$ in the calves fed diet A and $0.75 \mathrm{~kg}$ in the calves fed diet B. But there was no significant difference between the two groups in daily gain.

Jap. J. Zootech. Sci., 47, (9): 557-559.

1976. 9. 
Sato, Kobayashi, Shishido and Tomabechi

Table 1. Plasma glucose levels and TDN intake from the diets in calves

\begin{tabular}{|c|c|c|c|c|}
\hline \multirow{2}{*}{$\begin{array}{l}\text { Age } \\
\text { (week) }\end{array}$} & \multicolumn{2}{|c|}{$\begin{array}{l}\text { Plasma glucose level } \\
\qquad(\mathrm{mg} / 100 \mathrm{~m} l)\end{array}$} & \multicolumn{2}{|c|}{$\begin{array}{l}\text { TDN intake from the diets } \\
(\mathrm{kg} / \text { day })\end{array}$} \\
\hline & Group $A^{11}$ & Group $B^{2 \prime}$ & Group $A^{11}$ & Group $B^{21}$ \\
\hline 1 & $63.5 \pm 4.4$ & $56.9 \pm 1.0$ & - & - \\
\hline 2 & $67.9 \pm 2.3$ & $60.3 \pm 5.6$ & $0.06 \pm 0.01 \quad(0.04 \pm 0.01)$ & $0.07 \pm 0.01(0.04 \pm 0.01)$ \\
\hline 3 & $67.9 \pm 2.4$ & $66.6 \pm 4.2$ & $0.15 \pm 0.03(0.12 \pm 0.02)$ & $0.16 \pm 0.03(0.09 \pm 0.02)$ \\
\hline 4 & $62.7 \pm 3.2$ & $57.9 \pm 2.6$ & $0.29 \pm 0.05(0.17 \pm 0.04)$ & $0.24 \pm 0.03(0.11 \pm 0.03)$ \\
\hline 5 & $72.3 \pm 3.6 *$ & $58.3 \pm 3.5$ & $0.46 \pm 0.08(0.31 \pm 0.06)$ & $0.45 \pm 0.04(0.22 \pm 0.03)$ \\
\hline 6 & $73.6 \pm 2.6$ & $71.5 \pm 3.4$ & $0.65 \pm 0.06(0.37 \pm 0.07)$ & $0.61 \pm 0.07(0.32 \pm 0.03)$ \\
\hline 7 & $83.8 \pm 4.1 *$ & $70.5 \pm 2.1$ & $0.82 \pm 0.05(0.46 \pm 0.08)$ & $0.70 \pm 0.04(0.33 \pm 0.02)$ \\
\hline 8 & $94.0 \pm 3.6 *$ & $78.5 \pm 3.1$ & $1.15 \pm 0.04 *(0.70 \pm 0.05 *)$ & $0.99 \pm 0.06(0.52 \pm 0.05)$ \\
\hline 9 & $96.1 \pm 4.9 *$ & $81.8 \pm 3.8$ & $1.32 \pm 0.05 *(0.85 \pm 0.07 *)$ & $1.08 \pm 0.08(0.60 \pm 0.07)$ \\
\hline 10 & $98.6 \pm 5.5$ & $89.4 \pm 3.8$ & $1.13 \pm 0.06(0.57 \pm 0.09)$ & $1.10 \pm 0.07(0.48 \pm 0.06)$ \\
\hline 11 & $106.0 \pm 3.9 *$ & $90.9 \pm 2.8$ & $1.76 \pm 0.08$ 娄 $(1.19 \pm 0.10 *)$ & $1.33 \pm 0.10(0.91 \pm 0.08)$ \\
\hline 12 & $104.3 \pm 3.2 *$ & $94.6 \pm 2.6$ & $1.79 \pm 0.08(1.36 \pm 0.09)$ & $1.57 \pm 0.08(1.19 \pm 0.10)$ \\
\hline
\end{tabular}

Each value is expressed as mean \pm S. E. of 6 calves.

1) Calves fed diet A (TDN 75\%), 2) Calves fed diet B (TDN 65\%),

*, $\underset{*}{*} \underset{*}{*}$ : Significantly different from the comparable value of

Group $\mathrm{B}$ at $\mathrm{P}<.05(*), \mathrm{P}<.01(*)$ and $\mathrm{P}<.001\left(\begin{array}{c}* \\ *\end{array}\right)$.

The figure in parentheses is TDN intake from the concentrate diet.

In Table 1, plasma glucose levels and TDN intakes from the diets are shown. Plasma glucose levels in the calves fed diet A were significantly higher than those in the calves fed diet $B$ in $5,7,8,9,11$ and 12 weeks of age. This tendency is similar to the observations by Moтor et al6). They reported that blood sugar levels in the cows given high leve of TDN were higher than those in the cows kept on low TDN diet. In the present experiment, the difference in plasma glucose levels between the two groups seems to be affected rather by the levels of dietary energy intake than by hay to concentrate ratio.

In the early stage of growth, no significant difference between the two groups was shown in plasma glucose levels. Since the dry matter intake and TDN intake from the diets were small in amount in the early period of age, it seems that plasma glucose levels are not influenced by the diets given.

In the early period of age (1-4 or 5 weeks), plasma glucose levels changed little with age, then glucose levels increased progressively with increasing age in all the calves. In sheep, the decline of blood glucose levels in the first 4-5 weeks of age was the results of decreased glucose contents in red corpuscle, and plasma glucose levels maintained constantly during the first 4-5 weeks of age ${ }^{5}$. The results of the present experiment agree with those observations. WEBB et $a l^{7}$. reported that blood and plasma glucose levels increased with increasing age in calves fed whole milk fortified with nonfat milk soilds. From the present experiment, it seems that there is an increase in plasma glucose level with advancing age in calves fed solid food as well as fortified milk. MCCANDLESs and $\mathrm{DYE}^{8)}$ suggested that the decrease in blood glucose levels with age was related to the development of the rumen. But REID ${ }^{5)}$ concluded that other factors were involved in blood glucose decrease with age. HobGsos ${ }^{9)}$ reported that the rumen became functional like adult's when dietary dry matter intake had reached $1.5 \mathrm{~kg}$ per day in calves. Since 
daily intake of dry matter from the diets reached the level of $1.5 \mathrm{~kg}$ at 9 weeks of age in the present experiment, it is considered that the rumen of the calves developed functionally at this age (approximately 9 weeks old). Therefore, it seems unlikely that the high plasma glucose level in the latter period of age is attributable to immature development of the rumen. It is suspected that absorption of milk components from the abomasum, and increased propionic acid production in the rumen due to large intake of concentrate diet may be a cause for plasma glucose increase.

The authors thank Dr. S. Omori for his valuable suggestion and Miss T. Kishi for her help in language.

\section{References}

1) Leat, W. M.F., Physiology of Digestion and Metabolism in the Ruminant ed by A.T. Phillipson 211́-222. Oriel Press. England. 1970.

2) Hamada, T., S. Omori, K. Kameoka, and H. Morimoto, Bull Nat Inst Anim Ind 18: 1-6. 1968.

3) Attebery, J. T. and H. W. Colvin, J Appl Physiol 18: 1221-1225. 1963.

4) Wing, J. M., N. L. Jacobson, and R. S. Allen, J Dairy Sci 38: 1006-1016. 1955.

5) Reid, R. L., Aust J Agric Res 4: 213-223. 1953.

6) Motor, Y., M. Iizuka, and H. Nishimura, J Jap Vet Med Asso 25: 663-668. 1972.

7) Webb, D, W., H. H. Head, and C. J. Wilcox, J Dairy Sci 52: 2007-2013. 1969.

8) McCandless, E. L., and J. A. Dye, Am J Physiol 162: 434-446. 1950.

9) Hodgson, J., Anim Prod 13: 15-24. 1971.

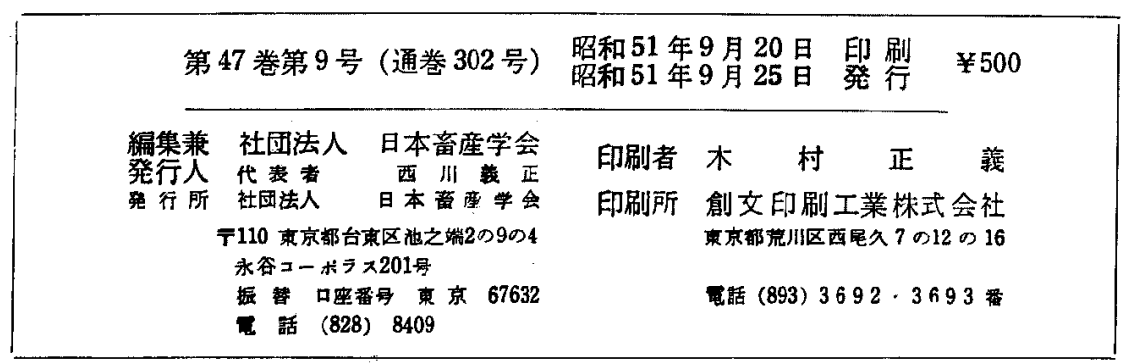

広告担当者 有限会社 瀬戸压告社 東京都文京区本郷 1-22-1 電話 (812) 4310, 6091

日蓄会報, $47(9)$ ：557-559.

1976. 9. 